JUNHUA GUO, Ph.D. ${ }^{1}$

(Corresponding author)

E-mail: gjhtougao@163.com

YUTAO YE, M.S. ${ }^{1}$

E-mail: 2018138085240001@ecjtu.edu.cn

YAFENG MA, Ph.D. ${ }^{1}$

E-mail: mayafeng1988@126.com

${ }^{1}$ School of Transportation \& Logistics

East China Jiaotong University

No. 808, Shuanggang East Avenue, Qingshan Lake

District, Nanchang, Jiangxi Province, 330013,

People's Republic of China
Traffic Engineering Original Scientific Paper Submitted: 5 May 2020 Accepted: 22 July 2020

\title{
ROUTE SELECTION AND DISTRIBUTION COST OF EXPRESS DELIVERY - AN URBAN METRO NETWORK BASED STUDY
}

\begin{abstract}
Route selection and distribution costs of express delivery based on the urban metro network, referred to as metro express delivery (MeD), is addressed in this study. Considering the characteristics of express delivery transportation and the complexity of the urban metro network, three distribution modes of different time periods are proposed and a strict integrated integer linear programming model is developed to minimize total distribution costs. To effectively solve the optimal problem, a standard genetic algorithm was improved and designed. Finally, the Ningbo subway network is used as an example to confirm the practicability and effectiveness of the model and algorithm. The results show that when the distribution number of express delivery packages is 1980, the three different MeD modes can reduce transportation costs by $40.5 \%, 62.0 \%$, and $59.0 \%$, respectively. The results of the case analysis will help guide express companies to collaborate with the urban metro network and choose the corresponding delivery mode according to the number of express deliveries required.
\end{abstract}

\section{KEYWORDS}

express delivery; metro network; improved genetic algorithm; path optimization.

\section{INTRODUCTION}

The world yearns for "low-carbon life, green travel," which has been reflected by more and more individuals seeking a green travel experience. In recent years, the development of the global logistics industry has led to the rapid growth of e-commerce scale. The number of express parcels is continually increasing, resulting in a higher proportion of express cargo transportation. According to recent statistics, China's express delivery business ranks first in the world and has for four consecutive years (2015 to 2018), with an average growth rate of $35.33 \%$ [1]. With an increasing number of express parcels, there is an urgent need for green express delivery transport with low costs, large volume, timeliness, and sustainability in modern city operations.

Passenger flow and cargo flow are mutually influential and interdependent in urban transportation systems [2]. From the perspective of green transportation combined with the characteristics of interconnection, innovation and sharing of innovative logistics [3], passengers and freight in a city are regarded as a single logistics system to achieve active and effective urban mobility [4]. In fact, sharing urban transportation resources and forming a strong coexistence between passengers and goods [5] are also reflected in the development trends of urban transportation systems [6], confirmed by passenger and goods transportation at airports [7].

In Sapporo, Japan, a special freight area was set up in subway cars and freight distribution services in subways were launched in 2010 [8]. Subsequently, Kyoto Prefecture launched the light rail freight service in 2011 using the existing light rail vehicles to deliver goods every morning before the peak of passenger flow [9]. This service effectively replaced traditional truck transportation. In New York, modified subway cars are used for the collection and transportation of subway waste [10]. Reece and Marinov [11] and Brice, et al. [12] suggested the use of the luggage transportation service from the city center to 
Newcastle Airport by metro and proved feasibility of the new luggage transfer system. Based on this research, a study conducted by Ghilas, et al. [13] found that a cargo transportation integrated with a scheduled line service reduces operating costs of the service provider, increasing additional income of the public transportation department. In addition, in Shanghai, China, "KSUDi", "East Union Express Company", and other small and medium-sized city express companies have used the metro for express delivery termed as metro express delivery (MeD).

To further study path selection and distribution costs of the MeD model, in the study presented here, three MeD models are proposed including the single-line-MeD outside operating period, multiple-lines-MeD outside operation period, and single-carriage-MeD during off-peak hours. The first and second delivery modes are based on an outside operation period that is also known as off-hour delivery [14]. The off-hour delivery is based on the fact that most metro-operated cities are relatively out of service due to insufficient passenger traffic. Therefore, when metro ends passenger transportation work, extended operation time is used for express delivery transportation. However, to the best of our knowledge, many cities exhibit lower passenger traffic during off-peak hours, resulting in a large amount of metro carriage space. Thus, another MeD mode is to select a metro carriage for express delivery during off-peak hours. Thus, two types of $\mathrm{MeD}$ and normal truck express delivery modes are compared in this study to estimate the feasibility of the MeD model and its ability to improve sustainability. A genetic algorithm is used to determine the two MeD and distribution modes in terms of cost, waiting time, feasibility, and sustainability.

Section 2 establishes three MeD models based on different time periods and Section 3 designs an effective improved genetic algorithm to solve this. Section 4 considers the metro network in Ningbo,
China as a practical case, compares and analyzes this traditional express delivery mode and $\mathrm{MeD}$ modes. Finally, conclusions and future research directions are provided in Section 5.

\section{THE MeD PROBLEM}

The MeD problem can be described as follows: In modern cities, the metro network consists of several metro lines, including metro stations and metro interchange stations. The express delivery of a city will arrive at a unified logistics park termed as express delivery center. Afterwards, express parcels are transported by vehicle to a corresponding metro station. After being transported by metro, parcels are transported by vehicle to final distribution points, termed as express delivery stations. As showed in Figure 1, the first and third stages include short-distance vehicle transportation that is used to connect the second stage, which is the metro distribution.

\subsection{MeD definitions and assumptions}

Express delivery vehicles provide specific on-demand transportation services from an express delivery center to metro entry stations or from metro exit stations to express delivery stations in the MeD. Transportation vehicles in the first and third stages begin transport before the assumed time period. Both metro lines and train departure schedules are fixed. The location coordinates of the express delivery center, each metro station and express delivery stations are all known. Express delivery demands of delivery stations are known and load capacity of the transport vehicle is certain.

The ultimate goal of the distribution process is to minimize overall transportation costs and costs related to the decision of allocating transportation vehicles and express delivery numbers.

To model the MeD problem, the following is assumed:

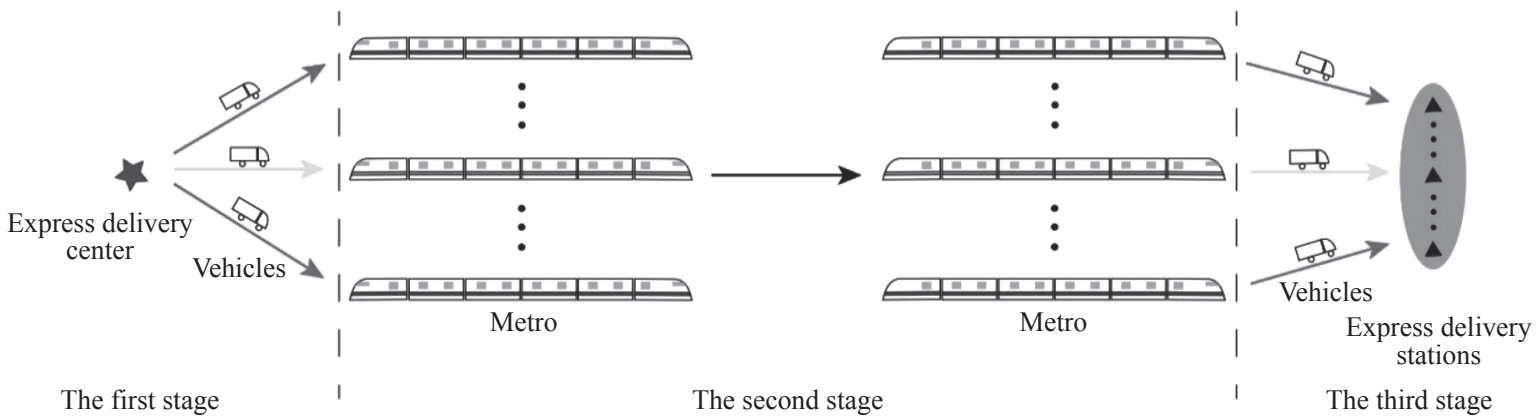

Figure 1-Metro express delivery (MeD) 
- The express delivery center $i$ and the express delivery stations cannot $i^{\prime}$ exceed a predetermined number, and the location is known.

- The express delivery transport demands $Q$ are known in advance.

- Express deliveries are transported to the metro for distribution without waiting for the metro to enter the station.

- After the express delivery leaves the express delivery center, it enters the metro system from the designated metro entry station.

- Vehicles that have been transported are not needed to return to the express center or metro exit stations.

- The total number of vehicles used for transportation is $K(K \in Z)$, and $K$ is an integer.

- The same vehicles are used for MeD and the capacity of each transport vehicle is $c a p_{v}$.
- On the same metro line, the number of express delivery's metro entry stations $j$ is equal to the number of metro exit stations $j j^{\prime}$.

- The cost of express delivery from the vehicle to the metro is included in the cost of metro transportation. The cost of the unit express delivery for one delivery is $C_{t}$.

\subsection{Single-line-MeD outside operation period}

Based on the running time of an urban metro, this article first considers completion of the metro operation and selects one metro line in the metro network for express delivery. The specific transportation process is shown in Figure 2. The express delivery from $j$ to $j$ ' is called one metro distribution line. Based on this, the following supplementary assumptions are proposed:

Table 1 - Summary of notations used throughout this manuscript

\begin{tabular}{|c|c|c|}
\hline \multirow{23}{*}{ 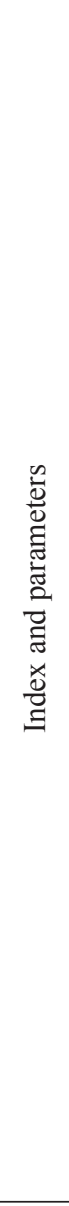 } & $j=1,2, \ldots, J$ & For metro entry stations \\
\hline & $j^{\prime}=1,2, \ldots, J^{\prime}$ & For metro exit stations \\
\hline & $i^{\prime}=1,2, \ldots, I^{\prime}$ & For express delivery stations \\
\hline & $v=1,2, \ldots, V^{\prime}$ & For vehicles $(n \in V)$ \\
\hline & $n$ & Index of vehicles \\
\hline & $m=1,2, \ldots, M$ & For metro \\
\hline & $i$ & Express delivery centers $(i=1)$ \\
\hline & $J$ & Number of metro entry stations \\
\hline & $J^{\prime}$ & Number of metro exit stations $\left(J^{\prime}=J\right)$ \\
\hline & $I^{\prime}$ & Number of express delivery stations \\
\hline & $V$ & Number of vehicles \\
\hline & $M$ & Number of the metro \\
\hline & $Q$ & Total amount of the express delivery \\
\hline & $Q_{i j}$ & Quantity of express deliveries delivered from $i$ to $j$ \\
\hline & $Q_{j j^{\prime}}$ & Quantity of express deliveries delivered from $j$ to $j^{\prime}$ \\
\hline & $Q_{j^{\prime} i^{\prime}}$ & Quantity of express deliveries delivered from $j^{\prime}$ to $i^{\prime}$ \\
\hline & $C_{v}$ & Fixed operating cost for one vehicle \\
\hline & $C_{i j}$ & Cost of the per unit express delivery transportation by vehicles from $i$ to $j$ \\
\hline & $C_{j^{\prime} i^{\prime}}$ & Cost of the per unit express delivery transportation by vehicle from $j^{\prime}$ to $i^{\prime}$ \\
\hline & $C_{i j^{\prime}}$ & Cost of the per unit express delivery transportation by metro from $j$ to $j^{\prime}$ \\
\hline & $C_{t}$ & Cost of the unit express delivery for one delivery \\
\hline & $\operatorname{cap}_{V}$ & Capacity of the transport vehicle \\
\hline & $\operatorname{cap}_{M}$ & Capacity of the transport metro \\
\hline \multirow{4}{*}{ 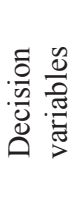 } & $x_{i j}^{v}$ & 1 if the transport path $(i, j)$ is served by the vehicle $v, 0$ otherwise \\
\hline & $x_{i^{\prime} j^{\prime}}^{v}$ & 1 if the transport path $\left(j^{\prime}, i^{\prime}\right)$ is served by the vehicle $v, 0$ otherwise \\
\hline & $y_{j j^{\prime}}^{m}$ & 1 if the transport path $\left(j, j^{\prime}\right)$ is served by metro $m, 0$ otherwise \\
\hline & $K$ & Quantity of the transport vehicles $(K \in Z)$ \\
\hline
\end{tabular}




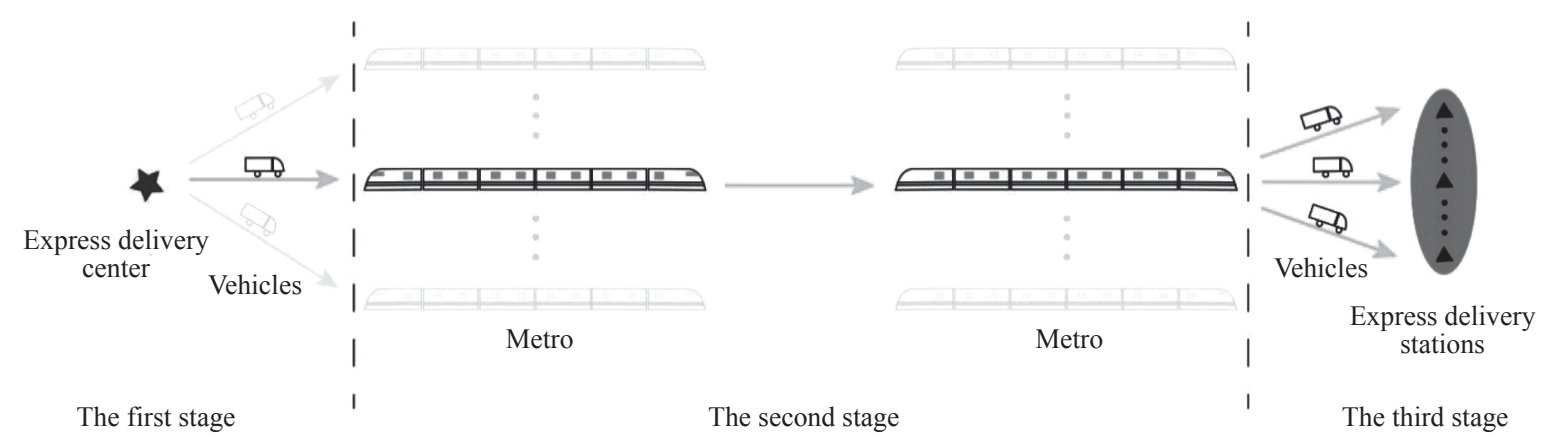

Figure 2 - Single line for MeD

- Considering the equipment overhaul after the metro operation, the metro train for express delivery distribution only performs one trip.

- All express deliveries are classified in the express delivery center based on the terminal express stations.

- All express deliveries exit from a single metro exit station and are transported by vehicles to various express delivery stations.

Next, we build a model step-by-step based on the three stages of the delivery mode. In the first stage, the vehicle path and capacity constraints are as follows:

$\sum_{j=1}^{J} x_{i j}^{v}=1 \quad i=1, v=1,2, \ldots, n$

$Q \leq \sum_{v=1}^{n} x_{i j}^{v} \operatorname{cap}_{v} \quad i=1, j=1,2, \ldots, J$

Equation 1 assigns a unique route for each vehicle from the express delivery center to the metro entry station. Equation 2 considers the number of vehicles in the first stage. Constraint Equations 1 and 2 determine the same route for all vehicles.

In the third stage, the path and capacity constraints of the vehicle are as follows:

$$
\begin{aligned}
& \sum_{j^{\prime}=1}^{j^{\prime}} \sum_{i^{\prime}=1}^{i^{\prime}} x_{j^{\prime} i^{\prime}}^{v}=1 \quad v=n, n+1, \ldots, V \\
& Q_{j i}^{\prime} i^{\prime} \leq \sum_{v=n}^{V} x_{j i}^{v}{ }^{\prime} \operatorname{cap}_{v} \quad j^{\prime}=1,2, \ldots, J^{\prime}, i^{\prime}=1,2, \ldots, I^{\prime}
\end{aligned}
$$

Equation 3 imposes that each vehicle can only have one unique route from one metro exit station to one express delivery station in the end delivery. Equation 4 determines the number of vehicles in the third stage.

Since the vehicles for transportation in the first and third stages are independent of one another, Equation 5 is proposed. The total number of vehicles in the entire distribution process also needs to be restrained as in Equation 6.

$$
K \geq 2
$$

$\sum_{v=1}^{n} \sum_{j=1}^{J} x_{i j}^{v}+\sum_{v=n}^{V} \sum_{j^{\prime}=1}^{j^{\prime}} \sum_{i^{\prime}=1}^{I^{\prime}} x_{i j^{\prime}}^{v} \leq K$

Equation 7 considers the conservation of the express delivery quantity.

$\sum_{j=1}^{J} Q_{i j}=\sum_{j=1}^{J} \sum_{j^{\prime}=1}^{j^{\prime}} Q_{j j^{\prime}}=\sum_{j^{\prime}=1}^{J^{\prime}} \sum_{i=1}^{I} Q_{j^{\prime} i^{\prime}}=Q \quad i=1$

Equations 8 and 9 represent constraints of the second phase regarding the metro distribution.

$\sum_{j=1}^{J} \sum_{j^{\prime}=1}^{j^{\prime}} y_{j j^{\prime}}^{m}=1 \quad m=1,2, \ldots M$

$Q \leq \sum_{j=1}^{J} \sum_{j^{\prime}=1}^{J^{\prime}} y_{j j^{\prime}}^{m}$ сар $_{M}=1 \quad m=1,2, \ldots M$

Equation 8 specifies the number of metros used for express delivery. Equation 9 expresses the metro capacity limit.

The single-line-MeD model consists of two objectives. The first objective describes the distribution cost of the vehicle under consideration (i.e., $\left.f_{v 1}\right)$. The second objective indicates the cost of the metro distribution, i.e., $f_{m 1}$. Without loss of generality, it is assumed that the objective is to minimize $f_{v 1}+f_{m 1}$. The first objective function $f_{v 1}$ is formulated as follows:

$$
f_{v 1}=\sum_{i=1} \sum_{j=1}^{j} \sum_{v=1}^{n} C_{i j} Q_{i j} x_{i j}^{v}+\sum_{j^{\prime}=1}^{j^{\prime}} \sum_{i^{\prime}=1}^{I^{\prime}} \sum_{v=n}^{V} C_{j^{\prime} i}^{\prime} Q_{j^{\prime} i^{\prime}} x_{j^{\prime} i^{\prime}}+K C_{v}
$$

In Equation 11, the first item represents total transportation costs of the vehicle. The first part of the equation includes the sum of total transportation costs of the unit express delivery from the express delivery center to the metro entry station. The second part of the equation indicates the sum of total transportation costs of the unit express delivery from the metro exit station to the express delivery station. The third aspect of the equation represents the fixed operating cost of vehicles.

The second objective function $f_{m 1}$ is formulated as follows:

$f_{m 1}=\sum_{j=1}^{J} \sum_{j^{\prime}=1}^{j^{\prime}} \sum_{m=1}^{M} C_{j j^{\prime}} Q_{j j^{\prime}} y_{j j^{\prime}}^{m}+2 C_{t} \sum_{j=1}^{J} \sum_{j^{\prime}=1}^{J^{\prime}} Q_{j j^{\prime}}$ 
Determination of total costs of metro transportation is as determined by Equation 12. In Equation 12, the first part of this equation includes the sum of total metro transportation costs, and the second aspect of the equation includes delivery costs from vehicle to metro.

Based on the delivery scene of a single metro line outside the operation period and considering constraints such as transportation route selection and distribution costs, single-line-MeD model is formulated as follows:

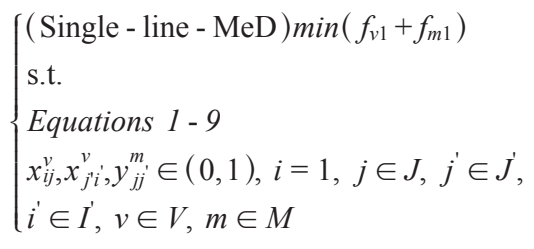

\subsection{Multiple-lines-MeD outside operation period}

Based on what was previously described, we proposed an express delivery method for multiple metro lines outside operating hours. The goal is to select a more reasonable and feasible distribution method by comparing the two delivery methods. This distribution method is described in Figure 3. The express delivery from the express delivery center is transported to metro stations by vehicles. Then, the express delivery can be transported by one or more metro lines through the metro interchange stations. Finally, deliveries are transported by vehicles to final express stations.

Based on this type of delivery system, this model was modified based on the model established in the previous section. The multiple metro lines distribution process is described by notations listed in Table 2 .

Assumptions and constraints are used to build the model as indicated:

- Each express delivery station $i^{\prime}$ has its own corresponding metro exit station $j^{\prime}$. Each metro exit station $j^{\prime}$ has its corresponding metro entry station $j$. Each metro entry station $j$ has one corresponding distribution line from $i$ to $j$.

$Q_{i j} \leq \sum_{v=1}^{n} x_{i j}^{v} c_{p a p} \quad i=1, j=1,2, \ldots, J$

Equation 1 and 16 represent different transport routes for metro entry stations.

- There are metro interchange stations in the metro network. A complete metro network, express delivery from one metro station to another results in up to two transfers.

$\sum_{j=1}^{J} O_{i j^{\prime}} \leq 2 \quad j^{\prime}=1,2, \ldots J^{\prime}$

- Due to the number of metro lines for express delivery, constraints have also changed.

$$
\sum_{j=1}^{J} O_{j j^{\prime}} \leq \sum_{j=1}^{J} y_{i j}{ }^{\prime} c a p_{M} \quad j^{\prime}=1,2, \ldots J^{\prime}
$$

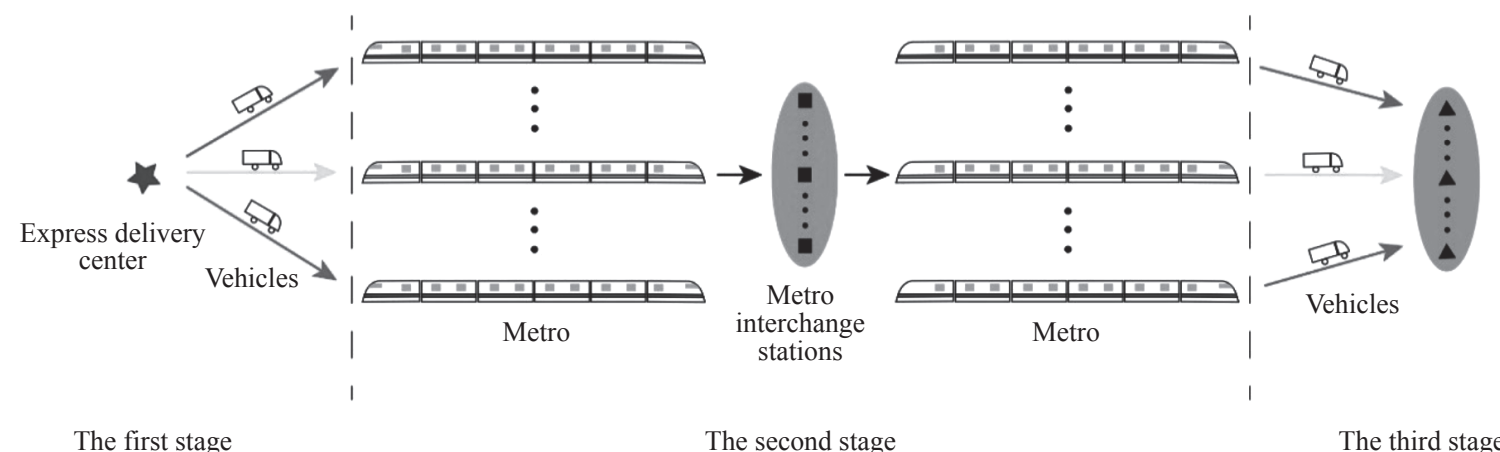

Figure 3 - Multiple-lines-MeD

Table 2 -Notations of the multiple metro lines distribution process

\begin{tabular}{||c||l|l||}
\hline \hline \multirow{2}{*}{$\begin{array}{c}\text { Index and } \\
\text { parameters }\end{array}$} & $o: 1,2, \ldots, O$ & For the metro interchange stations \\
\cline { 2 - 3 } & $O_{j j^{\prime}}$ & Number of the metro interchange stations \\
\hline $\begin{array}{c}\text { Decision } \\
\text { variables }\end{array}$ & $y_{i j j^{\prime}}$ & Cost of the per unit express delivery transfer through the metro interchange station $o$ \\
\hline
\end{tabular}


At this time, $f_{m 2}$ is formulated as follows:

$f_{m 2}=\sum_{j=1}^{J} \sum_{j^{\prime}=1}^{j} Q_{j j^{\prime}} y_{j j}\left[C_{j j^{\prime}}+C_{O}\left(O_{j j^{\prime}}+1\right)\right]$

Compared with the single-line-MeD, the multiple-lines-MeD increases transshipment costs of express delivery at the metro interchange station. Vehicle delivery costs $f_{v 2}$ are the same as $f_{v 1}$, where $f_{v 2}=f_{v 1}$.

Therefore, the multiple-lines-MeD model can be formulated as follows:

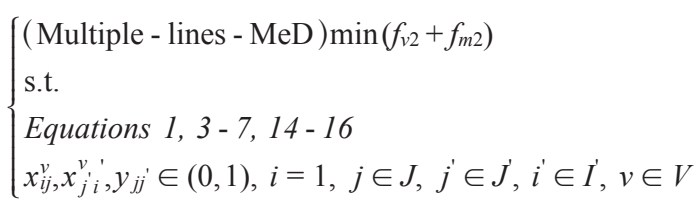

\subsection{Single-carriage-MeD during off-peak hours}

As assumed in subsections 3.2 and 3.3, the MeD model was constructed and there is no need to consider waiting for the metro to enter the station time, which is inconsistent with the normal metro operation. In addition to the running time period and the metro transportable express delivery capacity, the single-carriage-MeD mode is the same as the multiple-lines-MeD mode, as shown in Figure 4. Therefore, the single-carriage-MeD mode during off-peak hours is proposed, and the express delivery of the metro during off-peak hours is established to ensure that total transportation costs are minimized during passenger waiting time.

Several variable descriptions are presented in Table 3 before the model was built.

The model can be optimized by considering the following assumptions and explanations:

- Each metro has a total of $D$ carriages, but only one carriage can load the express delivery and contains capacity restrictions. At the same time, the number of times for metro transportation has also changed.
Table 3 - Variables of single-carriage-MeD mode

\begin{tabular}{||c|l||}
\hline \hline Variables & \multicolumn{1}{|c|}{ Definition } \\
\hline \hline$D$ & Number of metro carriages \\
\hline$N_{j j^{\prime}}$ & Number of times for metro transportation \\
\hline$t_{\text {wait }}$ & $\begin{array}{l}\text { Passenger waiting time for express } \\
\text { delivery loading to the metro carriage }\end{array}$ \\
\hline$T$ & $\begin{array}{l}\text { Total waiting time for express delivery in } \\
\text { the metro network }\end{array}$ \\
\hline$C_{T}$ & Cost of waiting per minute \\
\hline
\end{tabular}

$\sum_{j=1}^{J} N_{j j^{\prime}}=\left[\frac{\sum_{j=1}^{J} Q_{j j^{\prime}}}{\text { cap }_{M}}\right] j^{\prime}=1,2, \ldots, J^{\prime}$

$\sum_{j=1}^{J} Q_{i j} \leq \frac{\operatorname{cap}_{M}}{D} \sum_{j=1}^{J} N_{j j^{\prime}} y_{i j} j^{\prime} j^{\prime}=1,2, \ldots, J^{\prime}$

Equation 23 represents the number of times for metro transportation $([x]$ represents the smallest integer greater than $x$ ).

- After the metro stops in the platform, it starts to load express deliveries. The time spent minus the normal metro stop time is $t_{\text {wait }}$. It takes the same time to unload the express deliveries.

- The total waiting time is $T$. Each time the express transfer is performed, the waiting time is doubled.

$T=2 t_{\text {wait }} \sum_{j=1}^{J} N_{j j} y_{j j^{\prime}}\left(O_{j j^{\prime}}+1\right) j^{\prime}=1,2, \ldots, J^{\prime}$

- The cost of waiting per minute is $C_{T}$. $C_{T}$ is equal to the product of the per capita GDP per minute and the average number of passengers in the offpeak $N_{P}$ period in the city.

$C_{T}=\frac{\text { Per capita } G D P}{365 \cdot 24 \cdot 60} N_{P}$

Express delivery during the operation of the metro, in addition to the cost of metro transportation, will also consume costs during waiting time for loading express deliveries. Therefore, the costs of the metro transportation express delivery $f_{m 3}$ also changed.

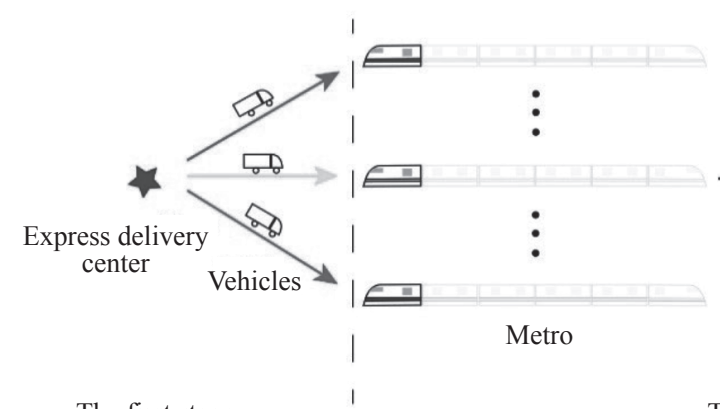

The first stage

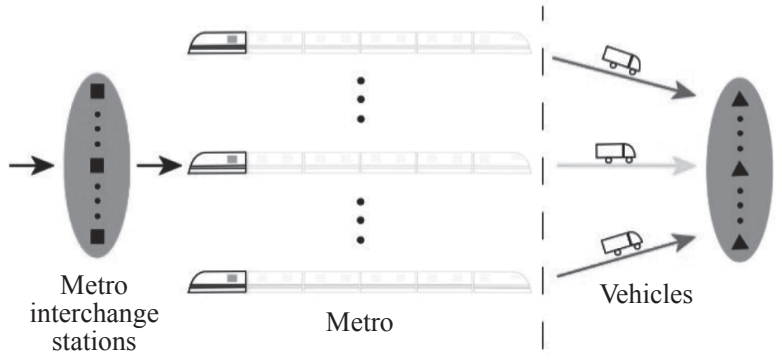

The second stage

The third stage

Figure 4-Single-carriage-MeD 
$f_{m 3}=\sum_{j=1}^{J} \sum_{j^{\prime}=1}^{j^{\prime}} Q_{j j^{\prime}} N_{j j^{\prime}} y_{j j^{\prime}}\left[\frac{C_{j j^{\prime}}}{D}+C_{O}\left(O_{j j^{\prime}}+1\right)\right]+T C_{T}$

However, vehicle delivery costs have not changed, $f_{v 3}=f_{v 2}=f_{v 1}$.

Therefore, the single-carriage-MeD model can be formulated as follows:

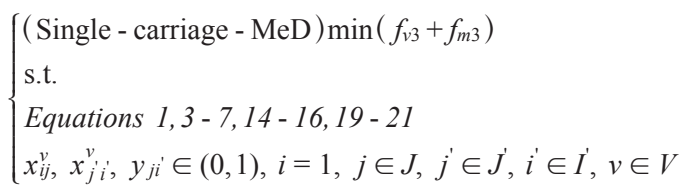

\section{SOLUTION APPROACHES}

In this paper, a nonlinear programming model is constructed and the results based on the gradient method or commercial optimization solver are not ideal. Therefore, the genetic algorithm is improved in terms of node [15] and path selection [16], and the constructed model is solved.

\subsection{Chromosome representation}

Considering the three stages of the express delivery process, the corresponding chromosome is divided into three gene fragments and natural number coding is adopted. Overall, determining the metro line for express delivery is the top priority of the transportation process. Binary code was used to express metro entry and exit stations and to decode the binary code to a decimal code, as shown in Figure 5. Applying a genetic operator to the chromosome encoded in Figure 6 forms a complete chromosome.

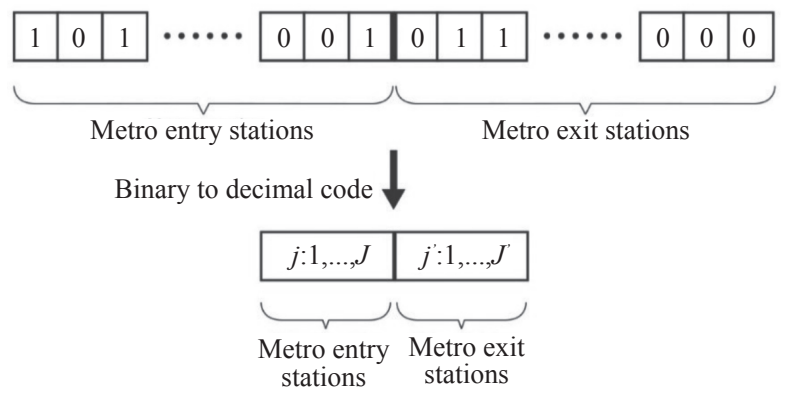

Figure 5 - Chromosome decoding

Since the originally generated chromosomal code is random, it is possible to generate an invalid chromosome containing a 0 encoded gene fragment. To solve this problem, Algorithm 1 was designed to check each chromosome. In Algorithm 1, gene fragments that were 0 are represented by $A$. The $z$ represents gene fragments with random numbers evenly distributed between $(0,1)$. Round the code in $\mathrm{z}$ into a new gene fragment and record it as $Z$.

Algorithm 1 - The checking procedure for each chromosome

Step 1: First, judge each chromosome. At the same time, the chromosome length is recorded as len. If the codes of the corresponding gene fragment are all 0 , pick out the chromosome $(A=$ zeros $(1$, len $)$; if $\operatorname{chrom}(1:$ len $)=A ; x=$ chrom; stop $)$, go to step 2 .

Step 2: A set of uniformly distributed random numbers from 0 to 1 is randomly generated using the rand function and rounded off. The newly generated 0,1 code replaces the corresponding gene fragment of the chromosome selected in step 1 ( $z=$ rand(1,len); $Z=$ round $(z))$, go to step 3 .

Step 3: For $i=1$ :Sizepop; while chroms $==A$, go to step 3; if $\operatorname{chroms}(i)=A$, go to step 2; stop. (Sizepop represents the population size, and chroms represents all chromosomes in the population.)

Step 4: There is no null chromosome in this population, stop.

\begin{tabular}{|c|c|c|c|c|}
\hline$i$ & $j: 1, \ldots, J$ & $j^{\prime}: 1, \ldots, J^{\prime}$ & $O_{i j j^{\prime}}$ & $i^{\prime}: 1, \ldots, I^{\prime}$ \\
\hline $\begin{array}{l}\text { Express } \\
\text { delivery } \\
\text { center }\end{array}$ & \multicolumn{3}{|c|}{$\begin{array}{l}\text { Metro entry stations, metro exit } \\
\text { stations, the number } \\
\text { of metro interchange points }\end{array}$} & $\begin{array}{l}\text { Express } \\
\text { delivery } \\
\text { stations }\end{array}$ \\
\hline & ure $6-$ & moson & ppos & \\
\hline
\end{tabular}

In Figure 6, the first gene fragment represents the first stage, where $i$ indicates the express center. The second gene segment represents the code of entry stations $(j=1,2, \ldots, J)$ and exit stations $\left(j^{\prime}=1,2, \ldots, J^{\prime}\right)$ as well as the number of transfer points required. The last gene segment represents the final express stations that need to arrive.

\subsection{The reverse procedure to determine a robust solution}

As known, standard genetic algorithms have disadvantages of poor local search ability and premature convergence, resulting in a solution result that is only a local rather than a global optimal solution.

The reverse procedure occurs after the selection, intersection and mutation procedures. It simulates gene order in biological chromosomes and the application of transgenic technology. There is a genome that can be visualized where genes are arranged in reverse order to form different chromo- 
somes. We use this process to reconstruct the gene segment of the metro into and out of a station. Firstly, the best chromosome with the most optimal fitness is screened. Secondly, two positions are randomly selected on the gene segment of both the entry and the exit stations in the chromosome to perform reverse operations (as shown in Figure 7). At the end, the reversed gene fragment replaces the position of the original gene fragment to form a new chromosome and calculate its fitness. If the fitness of the new chromosome is more optimal than the original chromosome, the new chromosome is replaced by the original chromosome in the population. The reverse procedure is presented in Algorithm 2.

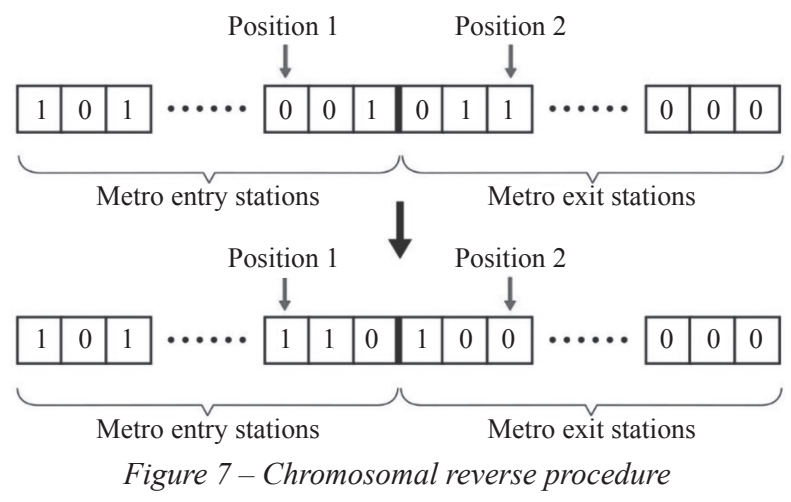

Algorithm 2 - The reversal procedure

Step 1: Set the index of the best chromosome and best fitness [bestchrom,bestfitness] $=$ Reverse (chrom,fun), go to step 2.

Step 2: Calculate the fitness of the best chromosome and record it as the bestfitness, go to step 3 .

Step 3: Two positions are randomly selected on the best chromosome (pos=randsample (1:len, 2 );

pos $=\operatorname{sort}($ pos);), and the reverse order is performed to form a new chromosome ( $x=$ bestchrom; $x(\operatorname{pos}(1): \operatorname{pos}(2))=x(\operatorname{pos}(2):-1: \operatorname{pos}(1)) ;$ new chrom $=x$ ). Go to step 4.

Step 4: Calculate the fitness of the newchrom and record it as newfitness, go to step 5 .

Step 5: Comparing the fitness of newfitness and bestfitness, if newfitness is better than bestfiness, newchrom replaces bestchrom (bestchrom=newchrom; bestfitness=newfitness;), otherwise it remains unchanged, stop.

\subsection{An improved genetic algorithm}

Other steps and approaches of genetic algorithms are similar to the standard GA algorithm and interested readers can refer to the related references [17]. The value of each chromosome is proportional to the value of the target function, which is used by the linqpro function in the MATLAB software to solve the linear programming problem. Specific details are operated based on Algorithm 3 presented below.

Algorithm 3 - The procedure of improved genetic algorithm

Step 1: Set initial parameters. (Pcross: probability of crossover; Pmutation: probability of mutation; Sizepop: population size; Maxgen: algebra requiring evolution; Lenchrom: chromosome length) Then, go to step 2.

Step 2: Data acquisition and pre-processing, the distance matrix of the express arrival center, the metro entry and exit stations, the final express stations, and the information of each metro line and station are imported. (load ij.mat; load jj'.mat; load j'i'. mat; load $O_{j j}$,mat; ), go to step 3 .

Step 3: Initialize Pcross, Pmutation, Sizepop, Maxgen, Lenchrom and other parameters, randomly generate the first generation population (population =struct ('chroms',zeros (sizepop,lenchrom), 'fitness', zeros (sizepop, 1));), go to step 4.

Step 4: Use Algorithm 1 to check whether the generated initial population contains invalid chromosomes, go to step 5.

Step 5: Selection procedure. Calculate the fitness of each updated chromosome, and use the method of roulette to screen and update the chromosomes in the population (sumfitness=sum(population.fitness); prob=population.fitness/sumfitness; index=randsample(1:sizepop, sizepop, 'true', prob);), go to step 6.

Step 6: Cross process. The chromosomes in the population are crossed and updated according to the crossover probability 'Pcross' ( $r=$ rand; if $r>$ Pcross, continue; stop), go to step 7.

Step 7: Mutation procedure. The chromosomes in the population are mutated and updated according to the mutation probability 'Pmutation' ( $r=$ rand; if $r>$ Pmutation, continue; stop), go to step 7 .

Step 8: Reverse procedure. Execution of Algorithm 2, stop. Go to step 8.

Step 9: Select the chromosome with the best fitness to get the lowest transportation cost and the optimal route.

\section{EMPIRICAL CASE STUDY}

\subsection{Data selection}

The metro network of the Ningbo Urban Rapid Rail Transit Construction Plan (2013-2020) is used as example [18] and is presented in Figure 8. 


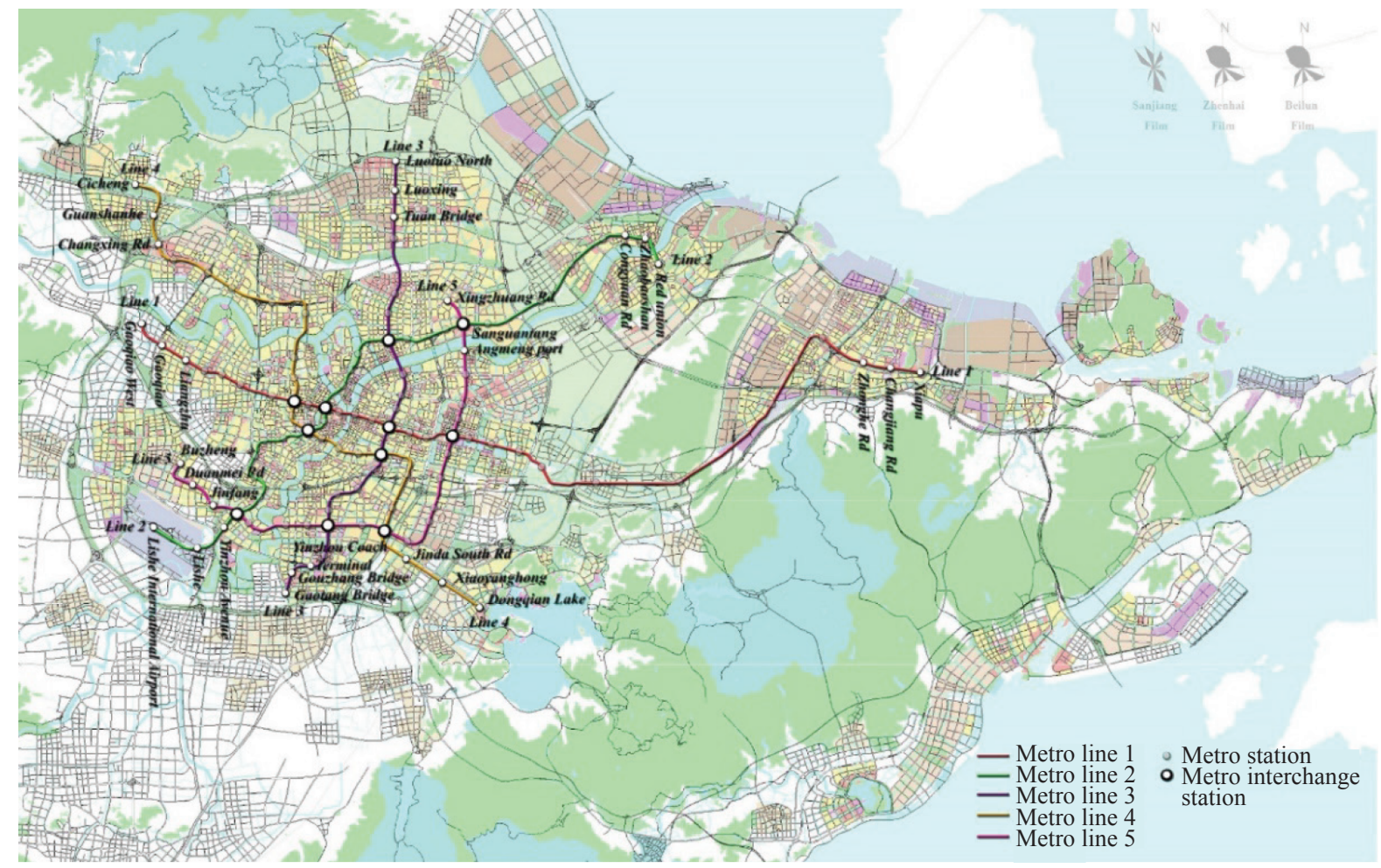

Figure 8 - Ningbo metro network schematic diagram

According to the Baidu Map API, the distance between the total express delivery station and the metro entry stations, the distance between the metro exit stations and the express delivery stations, and the number of stations between each metro entry station and exit station were obtained. Ningbo rail transit trains were grouped into 6 carriages containing a maximum capacity of 2,062 passengers, which corresponded to 1980 express delivery packages, consisting of 330 packages in each metro carriage. The capacity of the delivery vehicle was 60 packages. The distribution cost per unit express delivery distance by metro, the delivery cost for one-time unit express delivery, the distribution cost per unit distance by vehicles, and the fixed operation cost of vehicles were 0.1, 0.6, 2 and 30 , respectively [19]. Based on the data per capita GDP and average daily passenger load in Ningbo in $2018, C_{T}$ was equal to 59.8 yuan per minute. Meanwhile, combined with literature and questionnaire results, passenger acceptable waiting time $t_{\text {wait }}$ was determined to be 2 minutes [20].

\subsection{Solution analysis}

Since the eastern part of Ningbo City faces the sea, the airport logistics park was selected as the express delivery terminal in the west of Ningbo.
In addition, multiple distribution centers were selected in the coastal area of the eastern part of the city and the locations were evenly distributed. In Figure 9, 1 represents the express delivery center termed as airport logistics park, L1-L5 indicates each metro line, I1-I3 indicates each metro entry station and O1-O3 represents each metro exit station. Considering the actual situation and the model solution, three metro stations were selected at the beginning and at the end of each metro line as the corresponding metro entry and exit stations. $\mathrm{A}, \mathrm{B}$ and $\mathrm{C}$ are the final express stations including Jiaochuan Hub, the Global Economic and Trade Building and the Ningbo International Circuit.

Based on the example data presented and the improved GA algorithm, the optimal scheme for vehicles to be delivered separately was calculated and results of delivery costs were compared with the metro distribution mode as shown in Table 4. In this section, the three MeD modes were assigned as modes 1, 2, and 3 from top to bottom as shown in Table 4.

As seen from the results presented in Table 4, the costs of the MeD method were lower than the costs associated with the traditional vehicle transportation method, and as the number of express deliveries increased, the cost gap became more apparent. 


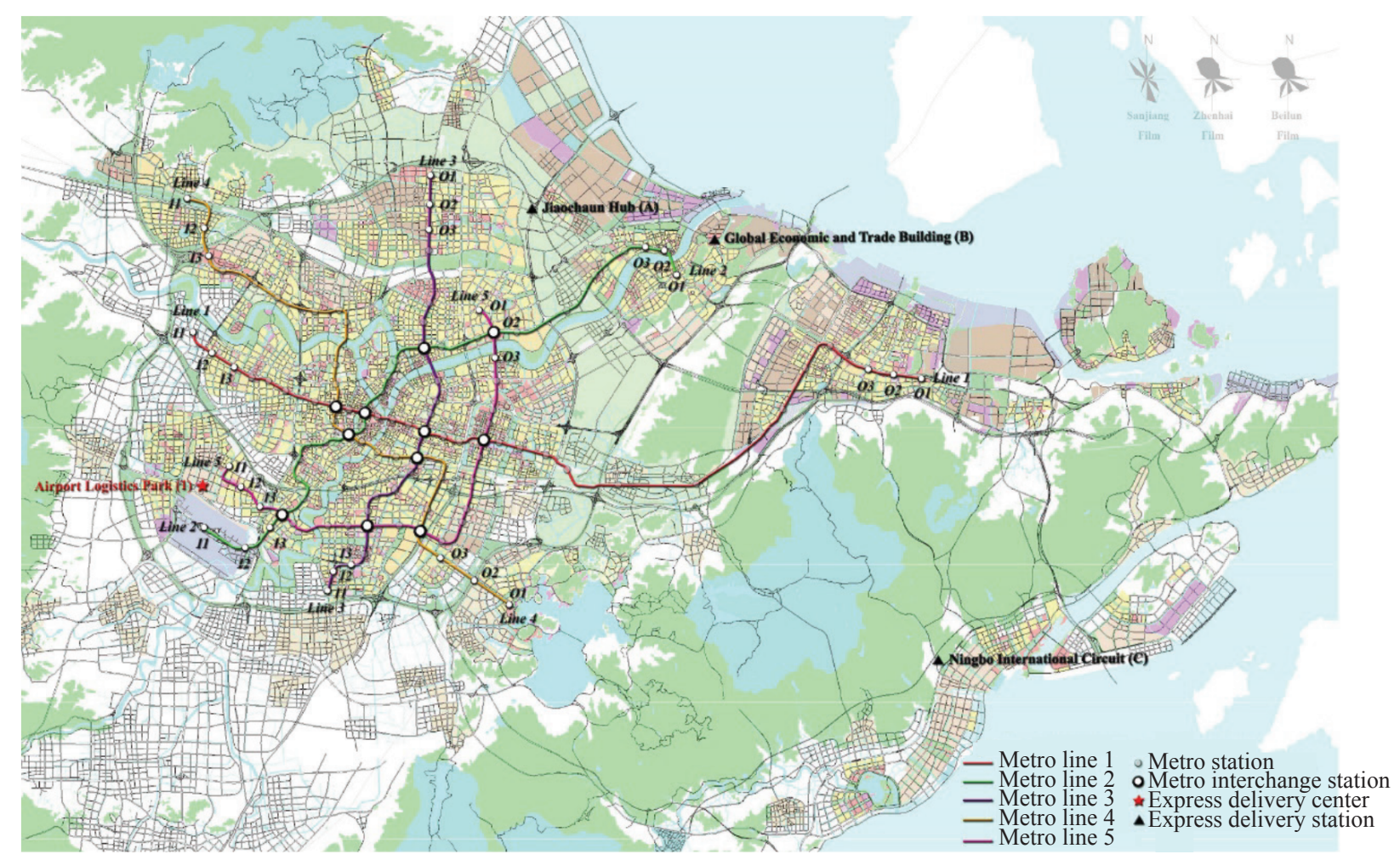

Figure 9 - A schematic diagram of distribution sites

Table 4-Comparison of four delivery modes

\begin{tabular}{||c|l|c||}
\hline \multicolumn{2}{||c|}{ Delivery method } & Total cost (yuan) \\
\hline \hline \multirow{3}{*}{ MeD } & Mode 1 (Single-line-MeD outside the operating period) & 98,010 \\
\cline { 2 - 3 } & Mode 2 (Multiple-lines-MeD outside the operation period) & $62,538.8$ \\
\cline { 2 - 3 } & Mode 3 (Single-carriage-MeD during the off-peak hours) & $67,558.2$ \\
\hline \multicolumn{2}{|l|}{ Vehicle delivery } & 164,670 \\
\hline
\end{tabular}

In addition, the lowest total costs of the three $\mathrm{MeD}$ modes were associated with the multiple-lines-MeD outside the operation period.

Table 5 presents results using an improved genetic algorithm to run the three MeD modes 100 times each. The failure rate in Table 5 indicates the number of running results above the average value. After many operations, the improved genetic algorithm designed in this study shows greater stability in obtaining better results and verifies the effectiveness of the algorithm presented here.
Table 6 contains information about the delivery process. Row 2 shows the express delivery route and the number of times for express delivery to transfer in the metro network. Row 3 shows the total distance driven by all vehicles when all express deliveries were completed. As seen in Table 6, the $\mathrm{MeD}$ method greatly reduces vehicle transportation distance, which not only saves on distribution costs, but also alleviates traffic congestion. Among the three MeD modes, modes 2 and 3 require the shortest vehicle delivery distances, followed by mode 1 .

Table 5 - Analysis of algorithm running results

\begin{tabular}{||c|c|c|c|c||}
\hline MeD & Best value (yuan) & Worst value (yuan) & Average value (yuan) & Failure rate [\%] \\
\hline \hline Mode 1 & $98,010.0$ & $98,010.0$ & $98,010.0$ & $0 \%$ \\
\hline Mode 2 & $62,538.8$ & $65,640.8$ & $63,144.9$ & $12 \%$ \\
\hline Mode 3 & $67,558.2$ & $69,835.2$ & $68,223.7$ & $16 \%$ \\
\hline
\end{tabular}


Table 6-Path comparison of the four delivery modes

\begin{tabular}{|c|c|c|c|c||}
\hline \multirow{2}{*}{ Delivery method } & \multicolumn{3}{|c|}{$\mathrm{MeD}$} & $\begin{array}{c}\text { Vehicle } \\
\text { delivery }\end{array}$ \\
\cline { 2 - 5 } & Mode 1 & Mode 2 & Mode 3 & $1 \rightarrow \mathrm{A}(0)$ \\
\hline \multirow{3}{*}{$\begin{array}{c}\text { Delivery route } \\
\text { (Transfer times) }\end{array}$} & $\begin{array}{c}1 \rightarrow \mathrm{L} 2 \mathrm{I} 1 \rightarrow \mathrm{L} 2 \mathrm{O} 1 \rightarrow \mathrm{A} \\
(0)\end{array}$ & $\begin{array}{c}1 \rightarrow \mathrm{L} 5 \mathrm{I} 2 \rightarrow \mathrm{L} 5 \mathrm{O} 2 \rightarrow \mathrm{A} \\
(0)\end{array}$ & $\begin{array}{c}1 \rightarrow \mathrm{L} 5 \mathrm{I} 2 \rightarrow \mathrm{L} 5 \mathrm{O} 2 \rightarrow \mathrm{A} \\
(0)\end{array}$ & $1 \rightarrow \mathrm{B}(0)$ \\
\cline { 2 - 5 } & $\begin{array}{c}1 \rightarrow \mathrm{L} 2 \mathrm{I} 1 \rightarrow \mathrm{L} 2 \mathrm{O} 1 \rightarrow \mathrm{B} \\
(0)\end{array}$ & $\begin{array}{c}1 \rightarrow \mathrm{L} 5 \mathrm{I} 2 \rightarrow \mathrm{L} 2 \mathrm{O} 1 \rightarrow \mathrm{B} \\
(1)\end{array}$ & $\begin{array}{c}1 \rightarrow \mathrm{L} 5 \mathrm{I} 2 \rightarrow \mathrm{L} 2 \mathrm{O} 1 \rightarrow \mathrm{B} \\
(1)\end{array}$ & $1 \rightarrow \mathrm{C}(0)$ \\
\cline { 2 - 5 } & $\begin{array}{c}1 \rightarrow \mathrm{L} 2 \mathrm{I} 1 \rightarrow \mathrm{L} 2 \mathrm{O} 1 \rightarrow \mathrm{C} \\
(0)\end{array}$ & $\begin{array}{c}1 \rightarrow \mathrm{L} 5 \mathrm{I} 2 \rightarrow \mathrm{L} 1 \mathrm{O} 3 \rightarrow \mathrm{C} \\
(1)\end{array}$ & $\begin{array}{c}1 \rightarrow \mathrm{L} 5 \mathrm{I} 2 \rightarrow \mathrm{L} 1 \mathrm{O} 3 \rightarrow \mathrm{C} \\
(1)\end{array}$ & 1,364 \\
\hline $\begin{array}{c}\text { Delivery distance by vehicles } \\
{[\mathrm{km}]}\end{array}$ & 716.1 & 422.4 & 422.4 & 1,4 \\
\hline \hline
\end{tabular}

In summary, based on the determined transport vehicle and metro capacity, the optimal delivery mode is mode 2 , which is the multiple-lines-MeD mode outside the operation period.

\subsection{Analysis based on the capacities of different distribution vehicles}

According to the conclusions formulated in the previous section, the sensitivity analysis of mode 2 was based on different distribution vehicle capacities. Table 7 summarizes the computational results for the different transport vehicle capacities. Columns 2 and 3 give the total costs of mode 2 and the total number of distribution vehicles under different vehicle capacities, respectively. Column 4 shows the proportion of fully loaded vehicles to the total number of vehicles under different distribution vehicle capacities. Full-load vehicle rates include the ratio of fully loaded vehicle number to the total number of delivered vehicles.

Table 7 -Different vehicle capacities

\begin{tabular}{|c|c|c|c|}
\hline \hline Distribution vehicle capacity $c a p_{V}$ & Total cost (yuan) & Total number of distribution vehicles & Full-load vehicle rate \\
\hline \hline 40 & $63,588.8$ & 101 & $96.04 \%$ \\
\hline 60 & $62,538.8$ & 66 & $100.00 \%$ \\
\hline 80 & $62,118.8$ & 52 & $92.31 \%$ \\
\hline 100 & $61,788.8$ & 41 & $90.24 \%$ \\
\hline
\end{tabular}

Table 8 - Different express delivery quantities

\begin{tabular}{|c|c|c|c|c||}
\hline \multirow{2}{*}{$\begin{array}{c}\text { Total amount of the } \\
\text { express delivery } Q\end{array}$} & \multicolumn{2}{|c|}{ Mode 2 } & \multicolumn{2}{|c|}{ Mode 3 } \\
\cline { 2 - 5 } & Total cost (yuan) & $\begin{array}{c}\text { Cost of metro distribution } \\
\text { (yuan) }\end{array}$ & Total cost (yuan) & $\begin{array}{c}\text { Cost of metro } \\
\text { distribution (yuan) }\end{array}$ \\
\hline \hline 330 & $10,456.3$ & $1,670.3$ & $11,289.7$ & $2,503.7$ \\
\hline 660 & $20,878.8$ & $3,336.8$ & $22,549.4$ & $5,007.4$ \\
\hline 990 & $31,331.3$ & $5,003.3$ & $33,839.1$ & $7,511.1$ \\
\hline 1,320 & $41,753.8$ & $6,669.8$ & $45,098.8$ & $10,014.8$ \\
\hline 1,650 & $52,206.3$ & $8,336.3$ & $56,388.5$ & $12,518.5$ \\
\hline 1,980 & $62,538.8$ & $10,002.8$ & $67,558.2$ & $15,022.2$ \\
\hline
\end{tabular}

In Table 7, the larger the capacity of the delivery vehicle, the lower the total costs, and the total number of distribution vehicles is reduced, which is consistent with the actual situation. Due to the capacity limitations of the distribution vehicle, the capacity of the delivery vehicle differs and the full-load vehicle rate also differs. When the distribution vehicle capacity is greater than 60 , the total cost reduction is not obvious and the full utilization rate of the delivery vehicle is gradually reduced. Therefore, it is not necessary to use a larger-capacity distribution vehicle in this delivery mode. In the future, multi-model vehicle distribution can be used to maximize the utilization of resources and further reduce costs.

\subsection{Analysis based on different express delivery quantities}

In this section, Table 8 shows the total distribution costs and metro distribution costs of models 2 and 3 based on different express delivery quantities. 


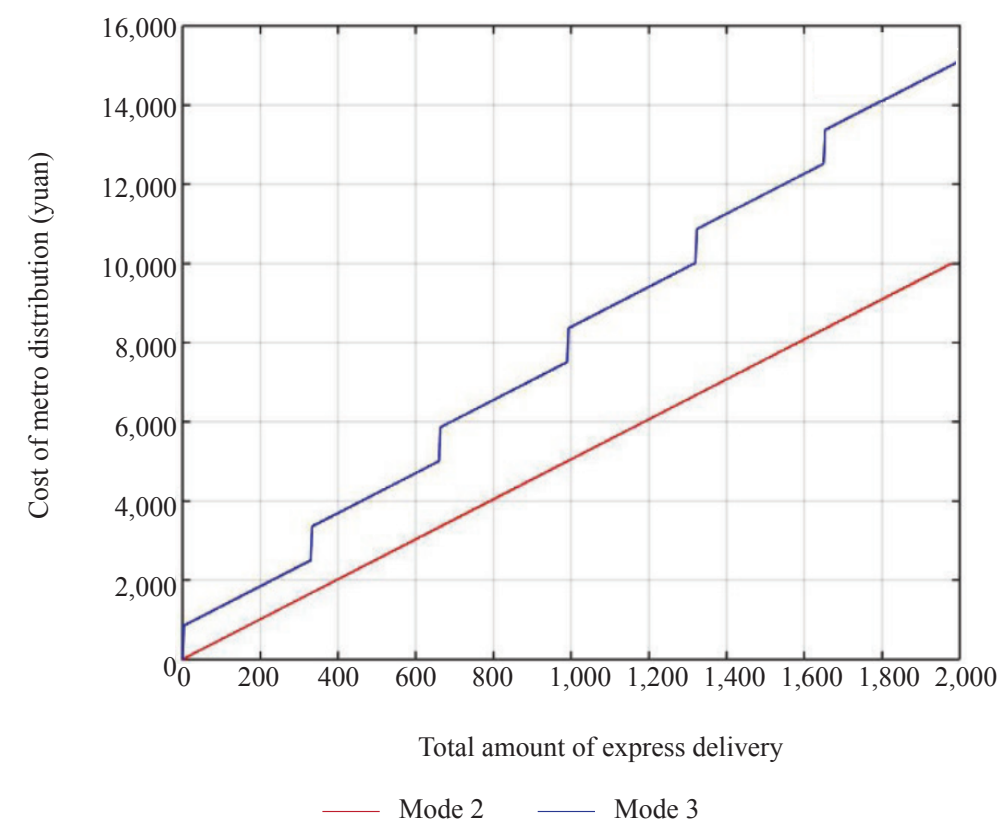

Figure 10 - Metro distribution cost of two modes based on different express delivery quantities

According to the results, as the quantity of express deliveries increases, distribution costs of models 2 and 3 also increase. The differences between the total distribution costs and the metro distribution costs of models 2 and 3 were the same, indicating that the vehicle delivery modes and costs of the two delivery modes were the same. The differences in costs of metro distribution lead to differences in the total distribution costs of the two methods. By comparing the metro distribution costs of modes 2 and 3 , the same number of express deliveries is transported, the total costs and metro distribution costs of mode 2 were always lower than what was observed for mode 3 .

To further analyze the metro distribution costs of the two distribution modes, the metro distribution cost maps of the two distribution modes were depicted. Since the two delivery modes were deployed by the maximum quantity of express delivery, they can be accommodated for the whole metro train, [0, 1980 ] as the interval for the express delivery quantities, as shown in Figure 10. As observed, with an increase in the quantity of express deliveries, the metro distribution costs of mode 2 show a linear growth trend, while the metro distribution costs of mode 3 show a periodic step-by-step growth. For mode 3, the single-carriage-MeD mode and the three final express stations are adopted so the growth trend is shown by 330 units of the express delivery in a cycle. In Figure 10, the same number of express deliveries is transported, and the metro distribution costs of mode 2 are always lower than in mode 3 .

\section{CONCLUSIONS AND FUTURE STUDIES}

In this paper, we propose a transportation method of the express delivery based on the urban subway network termed as metro express delivery $(\mathrm{MeD})$. Based on the goal of minimizing distribution costs, the route selection model of $\mathrm{MeD}$ was constructed, and genetic algorithms were designed and improved. Taking the metro network in Ningbo as an example, the distribution model based on different time periods was considered. While verifying the effectiveness of the algorithm, the following main conclusions were formulated:

- The costs of express delivery parcels for traditional road vehicles are much higher than the $\mathrm{MeD}$ mode. The transportation distance of the vehicle is greatly reduced when using the metro for express delivery. This indicates that the express delivery of the metro is feasible, more economical and more in line with the needs of urban development.

- By comparing the three distribution schemes, multiple metro line distributions are more optimal than single line distributions. From the perspective of distribution costs, the singleline-MeD mode is optimal, followed by the multiple-lines-MeD mode, and finally the single-carriage-MeD mode. In addition, different distribution vehicle capacities also have an impact on transportation costs. 
- Taking Ningbo City as an example, the model and algorithm were verified and analyzed, and the distribution of different vehicle capacities was shown to impact distribution costs. In addition, the same number of express deliveries is transported, the metro distribution costs of the multiple-lines-MeD mode is always lower than single-carriage-MeD mode.

Further studies should focus on several aspects. First, the space resource utilization rate of transportation means is not considered in the MeD mode. This step of loading costs requires further in-depth analyses. Moreover, the work presented here simplifies the express delivery model based on the urban metro net. Effective heuristics to solve the more realistic $\mathrm{MeD}$ model is also a subject of future research. The rapid development of e-commerce has contributed to the significant growth of express delivery services and the continuous improvement of service quality. How to explore a new and reasonable distribution mode on the basis of existing resources is worthy of continued in-depth exploration.

\section{ACKNOWLEDGEMENT}

This work was financially supported by the National Natural Science Foundation of China (71662011, 71940009).

郭军华, 博士 ${ }^{1}$

E-mail: gjhtougao@163.com

叶雨涛, 硕士 ${ }^{1}$

E-mail: 2018138085240001@ecjtu.edu.cn

马亚锋, 博士 ${ }^{1}$

E-mail: mayafeng1988@126.com

1 华东交通大学, 交通运输与物流学院

中国江西省南昌市青山湖区双港东大街808号，330013

\section{快递的路线选择和配送成本: 基于城市地铁网} 络的研究

\section{摘要}

这项研究解决了基于城市地铁网络的快递的路线 选择和分配成本, 称为地铁快递 $(M e D)$ 。考虑到 快递运输的特点和城市地铁网络的复杂性, 提出了 三种不同时段的配送方式，并建立了严格的集成整 数线性规划模型, 以使配送总成本最小化。为了有 效地解决最优问题, 对标准遗传算法进行了改进和 设计。最后以宁波地铁为例, 验证了该模型和算法 的实用性和有效性。结果表明, 当快递包裹的分发 数量为 1980 时, 三种不同的 $M e D$ 模式可以分别降低 运输成本 $40.5 \%, 62.0 \%$ 和 $59.0 \%$ 。案例分析的结果 将有助于指导快递公司与城市地铁网络合作，并根 据所需的快递数量选择相应的配送方式。
关键词:

快递; 地铁网络; 改进的遗传算法; 路径优化.

\section{REFERENCES}

[1] National Bureau of Statistics of China. Express Industry Developme Data. Available from: http://data.stats.gov. cn/easyquery.htm?cn=C01

[2] Goldman T, Gorham R. Sustainable urban transport: Four innovative directions. Technology in Society. 2006;28(12): 261-73. DOI: 10.1016/j.techsoc.2005.10.007

[3] Yang J, Guo J, Ma S. Low-carbon city logistics distribution network design with resource deployment. Journal of Cleaner Production. 2016;119: 223-8. DOI: 10.1016/ j.jclepro.2013.11.011

[4] European Commission. Towards a new culture for urban mobility. Green paper. European Union, Brussels; 2007.

[5] Trentini A, Mahléné N. Toward a Shared Urban Transport System Ensuring Passengers \& Goods Cohabitation. TeMA - Journal of Land Use Mobility Environmental Progress \& Sustainable Energy. 2010;3(2). DOI: 10.6092/1970-9870/165

[6] He Y, Yang S, Chan C-Y, Chen L, Wu C. Visualization Analysis of Intelligent Vehicles Research Field Based on Mapping Knowledge Domain. IEEE Transactions on Intelligent Transportation Systems. 2020;PP(99): 1-16. DOI: 10.1109 / TITS.2020.2991642

[7] Zhao PX, Gao WQ, Han X, Luo WH. Bi-Objective Collaborative Scheduling Optimization of Airport Ferry Vehicle and Tractor. International Journal of Simulation Modelling. 2019;18(2): 355-65. DOI: 10.2507/ ijsimm18(2)co9

[8] Kikuta J, Tatsuhide I, Tomiyama I, Yamamoto S, Yamada T. New Subway-Integrated City Logistics Szystem. Procedia - Social and Behavioral Sciences. 2012;39: 476-89. DOI: 10.1016/j.sbspro.2012.03.123

[9] Diziain D, Taniguchi E, Dablanc L. Urban Logistics by Rail and Waterways in France and Japan. Procedia - Social and Behavioral Sciences. 2014;125: 159-70. DOI: 10.1016/j.sbspro.2014.01.1464

[10] Metropolitan Transportation Authority. NYCT Trash Can Free Stations Pilot Update. Metropolitan Transportation Authority. Report Presentation, 2014.

[11] Reece D, Marinov M. Modelling the implementation of a baggage transport system in newcastle upon tyne for passengers using mixedmode travel. Transport Problem. 2015;10(4): 149-55. DOI: 10.1016/j.sbspro. 2014.01.1464

[12] Brice D, Marinov M, Rüger B. A Newly Designed Baggage Transfer System Implemented Using Event-Based Simulations. Urban Rail Transit. 2015;1(4): 194-214. DOI: 10.1007/s40864-015-0027-4

[13] Ghilas V, Demir E, Woensel TV. A scenario-based planning for the pickup and delivery problem with time windows, scheduled lines and stochastic demands. Transportation Research Part B: Methodological. 2016;91: 34-51. DOI: 10.1016/j.trb. 2016.04.015

[14] Holguín-Veras J, Wang C, Browne M, Hodge SD, Wojtowicz J. The New York City Off-hour Delivery Project: Lessons for City Logistics. Procedia - Social and 
Behavioral Sciences. 2014;125: 36-48. DOI: 10.1016/j. sbspro.2014.01.1454

[15] Zhang H, Tang L, Yang C, Lan S. Locating electric vehicle charging stations with service capacity using the improved whale optimization algorithm. Advanced Engineering Informatics. 2019;41. DOI: 10.1016/j.aei. 2019.02.006

[16] Zhang H, Cui Y. A model combining a Bayesian network with a modified genetic algorithm for green supplier selection. Simulation. 2019;95(12): 1165-83. DOI: 10.1177/0037549719826306

[17] Cheng R, Gen M. Genetic algorithms and engineering design. John Wiley; 1997.

[18] Ningbo Rail Transit. Ningbo Urban Rapid Rail Transit Construction Plan (2013-2020). Available from: http:// www.nbmetro.com/about_plan.php?info/72013

[19] Zhou F, Zhang J, Zhou G. Subway-based Distribution Network Routing Optimization Problem with Time Windows. Journal of Transportation Systems Engineering and Information Technology (in Chinese). 2018;18(5): 92-8. DOI: 10.16097 j.cnki.1009-6744.2018.05.014

[20] The People's Government of Ningbo. 2018 Ningbo Statistical Yearbook. Ningbo Municipal Statistics Bureau. Report number: 12, 2018. 